Original Research Paper

\title{
Jewish Identity and Volunteerism: Motivational Drivers in a Small North Carolina Temple
}

\author{
Renee Just \\ Peabody School of Education, Vanderbilt University, Nashville, USA
}

\author{
Article history \\ Received: 11-03-2021 \\ Revised: 13-04-2021 \\ Accepted: 18-04-2021 \\ Email:renee.just@vanderbilt.edu
}

\begin{abstract}
The purpose of this research was to examine Jewish identity and its impact on volunteerism and driving motivation in a small reform Temple in North Carolina. This study assessed the Jewish identity of members of the Temple and their motivation to volunteer within this congregation. Following from the research on identity and volunteerism, the primary focus was the extent to which the congregants embrace a Jewish identity and the level to which they perceive that volunteering at the synagogue is an expression of that identity. A mixed-methods design was crafted with the initial data collection obtained through a quantitative survey: The American Jewish Identity Scales (AJIS). Qualitative data were then collected through one audio-recorded, semi-structured focus group consisting of 7 volunteers. While the quantitative results showed that identity did not appear to be the driving factor for volunteering, the qualitative summary uncovered other identity-based motivations to volunteer. These motivations stemmed from one's own family as well as the perception of the Temple as an extension of family.
\end{abstract}

Keywords: Identity, Motivation, Identity-Based Motivation, Volunteerism

\section{Introduction}

The religious composition of the city includes more than 149 churches, one mosque and one temple (synagogue). The Temple represents the heart of the city's Jewish community and activities, welcoming members from all Jewish backgrounds, as well as guests of other faiths and beliefs. As the sole house of worship for Jews, it is important to note that the membership includes a variety of ages, gender identities, professions, personal interests, races and Jewish familial traditions and backgrounds. As a religious, social and educational center, the Temple is committed to promoting and providing opportunities for Jewish-based spiritual and religious enrichment.

The Temple offers its members opportunities to form meaningful connections with traditions and people by providing religious and cultural education and activities. These events are intended to encourage members to deepen their connections to the Temple and to support the city's Jewish population in addition to the broader community. Each of the activities and events require volunteers and volunteerism is a core belief of this Temple and the Union for Reform Judaism, which notes: "We believe that all human beings are created in the image of God and that we are God's partners in improving the world. Tikkun olam-repairing the world-is a hallmark of
Reform Judaism as we strive to bring peace, freedom and justice to all people" (urj.org).

In an effort to gain insight into the recruitment strategy for volunteers, how volunteers learn about opportunities, if the Temple leadership has an understanding of why or why not individuals volunteer and whether the development of a volunteer network was being addressed as a strategic initiative, time was spent speaking with the Rabbi, as well as with the current and immediate-past president. They unanimously agreed that "we are a 'plugged-in' society, always on the go, trying to juggle raising children, caring for elderly parents, working and attending to a plethora of family issues." Additionally, they believe that when parents reach a certain point in their children's lives (Bar/Bat Mitzvah), they retreat from being more active in the Temple because there is an impression that they have paid their (volunteer) dues. There was also a general consensus that people will volunteer for a particular event; however, it is often the same individuals who volunteer time and again. The current president theorized that one of the barriers to volunteering might be the time commitment expected when an individual assumes a leadership role because the commitment can range from just four hours per month to twenty or thirty hours per month.

The past-president offered insight by describing a timeline of the evolution of volunteerism at the Temple. 
She expressed that for the older generation of members (born in 1945 and earlier), the Temple was their "country club" of sorts because they had not been permitted to join the local country club simply because they were Jewish. The Temple was the place where they were accepted for being Jewish. It wasn't until a prominent community member was invited to join the (actual) country club that the door opened for other members of the Jewish community to join as well. The next generation (born approximately between 1946-1964) also viewed the Temple as their social hub. These individuals volunteered because their parents had volunteered and they felt it was important to carry on that tradition. The following generation (1965-1977) found that by this time being Jewish in the community at large was more accepted. Because there were numerous leadership opportunities as well as extracurricular activities available for their children (sports, music, dance), many parents began to volunteer their time in a manner that benefitted their families. While being part of the Jewish community is nice to have, this generation now also has other communities in which to divide their time and efforts.

With an insufficient number of volunteers for these leadership positions, the Temple is at risk for becoming stagnant because the incoming president finds it necessary to recruit previous board members (having served 5, 10, or even 15 years ago) in order to fill current positions. The disadvantages of this system include an outdated replication of past practices and a potential lack of relevance to today's congregants. In addition, there exists a gap in the needs of the community and in the educational programming offered by the Temple.

Notably, there is no formal plan for extending the recruitment efforts for volunteers beyond a board member's personal network or through announcements made during a regular Friday night Shabbat Service. Although the service attracts an average of 50 congregants each week, it is often many of the same individuals, which means that the outreach and communication to the congregation of the Temple in its entirety is incomplete.

\section{Literature Review}

Volunteerism is defined as an act of helping that is not based on monetary compensation but is instead a planned, willful action in which the foundation is to help others with a task or to improve their overall well-being (Penner, 2002; Finkelstein, 2009; Wilson, 2012). The motivation to volunteer, according to (Wemlinger and Berlan, 2016), is rooted in a common social need to engage in communal relationships. By definition, volunteers do not receive compensation for their efforts, so something other than extrinsic rewards must drive the decision to volunteer, most likely a need to satisfy a social or intrinsic need (Gage III and Thapa, 2012).

\section{Not-for-Profit Volunteerism}

While overall volunteerism has experienced a decline, researchers of religious volunteerism posit that when an individual's religious affiliation (church, temple, mosque, etc.) is rooted in interfaith initiatives, they are more apt to volunteer (Wemlinger and Berlan, 2016; Johnston, 2013; Lowe et al., 2019; Mencken and Fitz, 2013). In support of this, (Forbes and Zampelli, 2014) revealed a correlation in their research between church participation and volunteer activities. To that end, (Kang, 2016) extends that, more often than not, a volunteer will align themselves with organizations that support and promote their values, be they religious or social, which indicates a relationship between church participation and volunteer activities.

Additional research indicates that religious attendance has a positive influence on an individual's desire to volunteer and affects the type of volunteerism in which they engage (Merino, 2013; Van Tienen et al., 2011). In research conducted on Christian-affiliated institutions, (Johnston, 2013) demonstrated a correlation between religious service attendance and volunteerism over the adult lifespan. Additionally, he demonstrated a relationship between the importance of religion to individuals and their level of volunteerism with their religious institutions.

Researchers suggest that, in general, volunteers will align themselves with organizations that support and promote their values (Kang, 2016; Levy, 2012; Cohen, 2006). In some communities, volunteering is greatly valued and, in some instances, it is valued more than monetary contributions (Taniguchi and Thomas, 2011). Many religious organizations promote volunteerism as a social norm in an effort to invoke acts of moral goodness (Johnson et al., 2015).

These findings hold within the Jewish religion as well. Jews are more likely to volunteer within their own community when their identification with the institution is strong (Levy, 2012). Further, Jews are more likely to volunteer within the Jewish community if they practice historical traditions and rituals both inside and outside of the home (Hodgkinson, 1990; Beyerlein and Hipp, 2006).

Still, there is widespread difficulty convincing individuals to volunteer. The rate of volunteerism in the United States has been on a steady decline. In 2015, volunteerism dropped to its lowest rate since formal tracking of this data began (U.S. Department of Labor, Bureau of Labor Statistics, 2016). In the face of this decline, organizations are forced to compete for available volunteers within the community. As a result, staff of NotFor-Profit organizations (NFPs) are assuming responsibilities previously performed by volunteers, thereby placing an extra burden on administrative staff struggling to meet their mandates (Gage III and Thapa, 2012; Manetti et al., 2015). Volunteerism in the NFP arena is mainly dedicated to educational/youth services at $25.1 \%$, religious organizations at $33.3 \%$ and hospitals/healthcare at 7.4\% (U.S. Department of Labor, Bureau of Labor Statistics, 
2016). With that said, individuals also give freely of their time to special interests and social welfare organizations.

Religious organizations are a prime example of the decline in volunteerism due to their reliance on volunteers to maintain daily operations. Volunteer participation rates observed in religious organizations declined approximately $2.5 \%$ from the high of $36.5 \%$ in 2007 (U.S. Department of Labor, Bureau of Labor Statistics, 2005; 2007; 2016). Volunteers not only serve the religious community and organization; they also assume critical operational roles in order for temple leadership to focus on the longer-term agenda. It is common practice for the Jewish religion to rely on lay leadership for important work in the daily operations and sustainability of the synagogue, fulfilling both board and committee positions.

\section{Motivation to Volunteer}

Volunteering means doing something without extrinsic reward. Therefore, volunteering is a result of intrinsic motivation, which can be driven by many factors. There may be any number of reasons that individuals will engage in the same task and yet will be motivated in completely different ways (Kwok et al., 2013). For some, the motivation to volunteer may be social relationships or interpersonal phenomena (Snyder and Omoto, 1992). Volunteers who are provided an opportunity that aligns with their personal motivational needs will be more likely to engage in volunteerism (Kwok et al., 2013). Personal motivational needs may be represented as values, beliefs, feelings, inspirational, religious, identity and any other identifier specific to each individual (Alexander et el., 2015).

In their research to further examine the motivators behind volunteerism, (Van Tienen et al., 2011) differentiate between formal volunteerism (public in nature and in concert with an organization) and informal volunteerism (more spontaneous and carried out in a more private setting or through one's network). They assert that religion and intrinsic motivation are functions of informal volunteering and uncover a connection between religious attendance and formal volunteering.

The research shows that volunteerism is often driven by faith and identification with the values of a faith. This is consistent with the research that indicates that individuals are driven toward volunteerism by intrinsic motivation. Researchers contend that when individuals feel a connection in the form of identity, their willingness to volunteer increases. Further, when values are supported as a component of identity, individuals give freely of their time (Levy, 2012; Chase, 2018; Punzi and Frischer, 2016).

\section{Identity}

The word "identity" has countless definitions, therefore, for the purpose of this article, the term is defined as a sense of sameness that is unwavering, an awareness of common characteristics and a sense of belonging to one's group (Chase, 2018). This definition aligns with the research of (Friedlander et al., 2010) (Cohen and Hill, 2007; Krieger, 2010) that Jewish identity is comprised of two core factors: Religious identity and cultural identity. Schlosser (2006) describes the cultural aspect as "All at once, Judaism is a culture, a religion, an ethnicity and a set of traditions that is embedded in Jewish people's expectations, belief systems and family dynamics." This stems from historical knowledge that the Jewish people have been identified as a cultural group for over 3,000 years and were once identified as the minority, the other, nonwhite and of 'other' ethnicity (Altman et al., 2010; Chase, 2018; Friedlander et al., 2010; Rosen, 2006). Core values in the Jewish identity are chesed (good deeds) and tikkun olam (repair the world) and when carried out, these actions provide structure and richness to the community as a whole. These core tenets, along with 613 commandments, can be found in the Torah and the Talmud. In a 2015 study by the Pew Research Center, Jews were asked about behaviors and attributes that are "essential" or "important" to their Jewish identity. In addition to remembering the Holocaust, Jews in the United States cite leading an ethical and moral life, working for justice and equality, observing Jewish law and caring about Israel as essential to being Jewish. Therefore, an argument can be made that if a Jew is living a Jewish life (following the commandments, performing good deeds and repairing the world), then their Jewish identity can also be considered a foundational feature of their identity as an individual.

Through an exploration of congregational communities and the dependence on people for programming, structure and strategies, (Nauta, 2007) purports that social processes are an intricate component of identity development and further contends that there is a balance that exists between religious identity and the decline of a congregation's vitality. Research has discovered that in recent years, a congregation's participation and involvement in religious institutions has been on the decline because the need to commit as a congregant is less important than in preceding decades (Nauta, 2007; Twenge et al., 2015). When religious identity declines, volunteerism declines as well.

Jewish identity is both multifaceted and multicultural and the dimensions of Jewish identity examined in the American Jewish Identity Scales (AJIS) have been identified as religious identification and cultural identification, which are both key to this study.

\section{Theoretical Framework}

Identity-Based Motivation (IBM) is the theoretical framework that is employed throughout this study. This framework rests on the assumption that one's identity matters because it imparts a foundation for meaningmaking (Oyserman, 2015). When individuals consider their own identity, they generally know who they are and that understanding is an important factor in what they do.

According to (Oyserman, 2015), identity-based motivated behavior is predicted by three elements as shown 
in Fig. 1: Dynamic construction of identity cues, actionreadiness and interpretation of difficulty. Individuals make sense of situations as they are occurring and assess them for action and identity cues. Individuals focus on who they are in a congruent manner, all while understanding that their identity can be fluid and may be impacted by personal circumstances and environmental cues (Oyserman, 2015). If an action feels identity-congruent, then the resulting behavior or action will not only feel right, the difficulty will also be interpreted as being more meaningful. Conversely, when behaviors or actions are identity-incongruent, then the difficulty will be interpreted as pointless or not for "people like me." Individuals place information in context in order to make sense of it. A situation is assessed in the context of taking action and the information that is present in the environment will affect the decision to do so. Although there are many sources of motivation, identity may also be a motivational force.

Beyond the membership beliefs and identity, researchers argue that IBM is about more than simple membership; specifically, it encompasses action-readiness and procedural-readiness. Action-readiness refers to how individuals behave in ways that people within their identity group seem to act; ways that feel right. Proceduralreadiness involves making sense of situations through the lens of an I/we (in-group) identity-congruent mindset (Oyserman, 2009; Lewis Jr and Oyserman, 2016). Lewis Jr and Oyserman (2016) further state that the three elements of identity-based motivation (dynamic construction, actionreadiness and interpretation of difficulty) act in tandem: One component activates the other.

Moreover, researchers claim that IBM links both cultural and societal identities and shapes the context that triggers goals, which motivates behavior (Klein et al., 2015). Notably, (Oyserman, 2007) classifies identities as personal (those traits or characteristics not originating from a social group) or social (stemming from social connections or broader categories). In their research to test dynamic construction, (Elmore and Oyserman, 2012) randomly assigned middle-school students to interpret either graphs depicting census information related to earnings or high school graduation rates in their state. To further dissect the graphs, some were delineated by gender. As the researchers predicted, in situations where boys examined graphs containing males, that information cued their interpretation baseline. Students displayed action-readiness after they read about the cost of a college education. The students began planning to study more and seek out opportunities for extra credit with the hope of increasing their grades, leading to financial rewards. Finally, in order to examine interpretation of difficulty, students were split into two groups. Group "A" was provided an interpretation of difficulty as a means to understand that schoolwork was important and in turn Group "A" tended to work harder on their homework and developed a higher quality of writing skills (Oyserman, 2015).

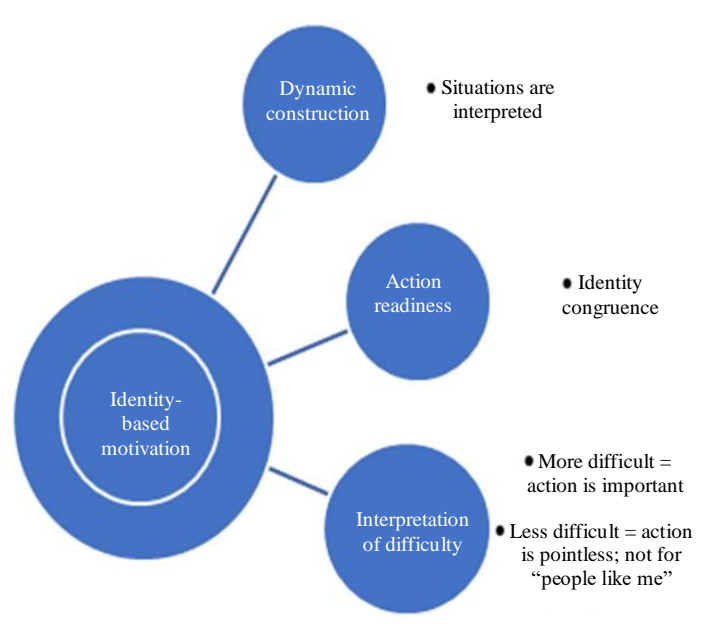

Fig. 1: Identity Based Motivation

Thus, given the research on volunteerism and identity and particularly on volunteerism in faith-based communities, including the Jewish faith, the goal is to understand how identity is, or is not, triggered in the context of volunteering at the Temple.

\section{Methodology and Instrument}

The AJIS is a psychological measure of Jewish identity that is used with "self-identified" American Jews regardless of one's individual affiliation or historical religious practices. Friedlander et al. (2010) developed the AJIS to assess cultural and religious identification of North American Jews. Because the scope was North American Jews, the researchers refer to "culture" as opposed to "ethnic" because culture is often associated with learned behaviors/beliefs and ethnic often refers to nationality and where an individual is from.

The survey was distributed to 399 Temple members via email, inviting them to participate in this research project. In the end, 386 surveys were returned. However, only 147 respondents fully completed the survey, which represents a $38.08 \%$ response rate. Qualitative data were then collected through one audio-recorded, semi-structured focus group consisting of 7 volunteers. The audio-recording of the focus group was transcribed verbatim and was uploaded into NVivo 12 software for thematic analysis. The focus group was conducted via Zoom, which allowed for a safe environment in light of COVID-19 and social distancing restrictions. To furtherunderstand the Jewish identity as it relates to volunteerism, questions asked during the focus group were:

1. What motivates you to volunteer at Temple?

2. Does your identity as a Jew impact your volunteerism?

3. Tell me about a time in your life when you felt your Jewish identity most deeply.

4. Are you aware of volunteer opportunities at Temple?

5. Do you carry out volunteer work other than at Temple? 


\section{Analysis}

The results were calculated and estimated using SPSS. The data were collected using an online survey of members of the Temple community. In this first section, the results are interpreted as standalone analyses, however, in the summary of this segment, the quantitative results are discussed in tandem with the qualitative results which are presented in the second section.

Based on the review of the literature, there were two key questions guiding this project:

1. To what extent do congregants identify with the Jewish faith?

2. To what extent do congregants see volunteer opportunities as expressions of their faith?

\section{Descriptive Statistics}

Descriptive statistics, including the means and standard deviations (for AJIS, continuous variable), were calculated for the study variables. Table 1 provides the distributions of the independent variables. A total of 147 respondents completed the survey. Among them, 97 (66\%) were female and 49 (44\%) were male. By birth cohort, respondents were distributed as follows: Respondents born in 1945 or before represented $20 \%$ of the sample $(n=30)$, those born between 1946 and 1964 composed $55 \%$ of the sample $(n=81)$, those born between 1965 and 1977 accounted for $14 \%$ of the sample $(n=1)$ and those born between 1978 and 1998 represented the remaining $10 \%$ of the sample $(n=15)$.

The employment status of the Temple congregants is presented in Table 1 as well. Of the sample, $45 \%$ of the congregants were retired $(n=66), 41 \%$ were employed fulltime $(n=60), 10 \%$ were working part-time $(n=14)$ and $5 \%$ of the congregants were unemployed $(n=7)$.

The survey also asked respondents if they had ever volunteered for the Temple. The vast majority, $123(84 \%)$ answered in the affirmative and only $16.3 \%(n=24)$ said they had not. The final descriptive/baseline questions asked of respondents pertained to the factors that impeded or influenced their decision to volunteer. Of the 123 participants who had volunteered in the past, the majority of participants gave personal satisfaction $(100,81.3 \%)$ and Mitzvah $(90,73.2 \%)$ as their reasons for volunteering. Of the 24 participants who had not volunteered in the past, the majority $(11,45.8 \%)$ claimed that the reason they could not volunteer was due to either work or personal scheduling conflicts (Table 2).

The participants' responses to the 33-survey item questions in the American Jewish Identity Scales (AJIS) are used to construct a summative scale. The highest possible score for the AJIS is 132. Each respondent was asked to rate the 33 items of the AJIS from 1 (Not at all true of me) to 4 (Very true of me) to represent how strongly they identify with each statement. A summative score was computed for each respondent to indicate their Jewish identification, which makes the independent variable a continuous variable. The higher the score, the more strongly the respondent identifies with the cultural and religious beliefs of Jewish people. As shown in Table 3, across the 147 respondents, the scores ranged from 41 to $111(M=74.7, S D=12.4)$. To test the associations among the demographic variables, volunteer history and Jewish identity (using AJIS), the following test approaches were employed. First, in order to examine the relationship between Jewish identity and the demographic variables, a series of ANOVAs were run (Tables 4-6). ANOVA was used because the factors-demographic variables-were categorical in nature and the AJIS variable was continuous. To examine the relationship between volunteer history and the demographic variables, a series of Chi-square analyses were conducted. This was appropriate because both the demographic and the volunteer history variables were categorical. Of the Chi-square associations among the demographic and volunteer variables, the only significant association occurred between generation and volunteer $($ Chi-square $=13.40, p=0.004)$. This indicates that different generations had different volunteer practices. Participants born between 1946 and 1964 had the highest numbers of volunteering experience.

Table 1: Frequencies and Percentages of Demographic Characteristics $(\mathrm{N}=147)$

\begin{tabular}{llrr}
\hline & & Frequency & Percent \\
\hline Birth cohort & Born 1945 or < & 30 & 20.4 \\
& Born between 1946-1964 & 81 & 55.1 \\
& Born between 1965-1977 & 14.3 \\
& Born between 1978-1998 & 21 & 10.2 \\
Gender & Total & 15 & 100.0 \\
& Female & 147 & 66.4 \\
Employment status & Male & 97 & 33.6 \\
& Total & 49 & 100.0 \\
& Full-time & 146 & 40.8 \\
& Part-time & 60 & 9.5 \\
& Retired & 14 & 44.9 \\
Have you & Unemployed & 66 & 4.8 \\
Volunteered for temple before? & Total & 7 & 100.0 \\
& No & 147 & 16.3 \\
& Yes & 24 & 83.7 \\
& Total & 123 & 147 \\
\hline
\end{tabular}


Finally, a comparison between AJIS and the volunteer history was performed using an ANOVA model (Tables 4-7).

Of the comparisons among AJIS and the demographic variables, there were no significant differences shown in terms of age, gender, or employment status. This indicates that an individual's Jewish identity does not relate to the demographic variables used in this sample.

Table 7 depicts the ANOVA results for Jewish identity and volunteer. The results in this sample were not significant, which indicates that whether an individual volunteered did not differ based on their Jewish identity.

\section{Quantitative Summary}

This section presents summary analysis of the quantitative component of the study of volunteers and the Temple. The descriptive statistics provided essential characteristics of the population and systematically examined the level of volunteerism among the congregants. Overall, the rate of volunteerism was very high: $84 \%$.

The ANOVAs did not show any significant effects determining either AJIS or likelihood to volunteer. The limitations of the data may be responsible for that result (hence, the qualitative component). For example, the group of non-volunteers is extremely small $(n=24)$.

\section{Qualitative Results}

Qualitative data were collected through one audiorecorded, semi-structured focus group of volunteers. Table 8 indicates the demographic characteristics of the individual focus group participants. Further, the question related to volunteering is a binary variable. As such, it may not account for different levels-or intensity-of volunteering, which may well still be affected by the degree of Jewish identification, as discussed in the qualitative data analysis.

The audio-recording of the focus group was transcribed verbatim and was uploaded into NVivo 12 software for thematic analysis. First, a cycle of open coding was conducted in which statements from the transcript were grouped when they expressed similar ideas or experiences.

Table 2: Reasons for Volunteering $(\mathrm{n}=123)$ or Not Volunteering

\begin{tabular}{lcc}
\multicolumn{1}{c}{$(\mathrm{n}=24)$} & Frequency & Percent \\
\hline Volunteering & 39 & \\
Friends volunteer & 42 & 31.7 \\
Social networking & 90 & 34.1 \\
Mitzvah & 100 & 73.2 \\
Personal satisfaction & 14 & 81.3 \\
Volunteerism recognized & 23 & 11.4 \\
Support is provided & 14 & 18.7 \\
None of the above & & 11.4 \\
Not Volunteering & 3 & \\
Lack skills/training & 1 & 12.5 \\
Lack of expectations & 0 & 4.2 \\
Financial difficulties & 1 & 0.0 \\
No transportation & 6 & 4.2 \\
Lack of time & 0 & 25.0 \\
Lack child/elder care & 11 & 0.0 \\
Work/personal conflict & 9 & 45.8 \\
None of the above & & 37.5 \\
\hline
\end{tabular}

Table 3: Descriptive Statistics of the American Jewish Identity Scales ( $=147)$

\begin{tabular}{|c|c|c|c|c|c|c|}
\hline \multirow{2}{*}{\multicolumn{2}{|c|}{ American Jewish Identity Scales (AJIS) measure }} & $N$ & Min & Max & Mean & Std. Dev \\
\hline & & 147 & 41 & 111 & 74.7 & 12.4 \\
\hline & Sum of squares & df & \multicolumn{2}{|c|}{ Mean square } & $\mathrm{F}$ & Sig. \\
\hline Between groups & 633.732 & 3 & \multicolumn{2}{|c|}{211.244} & \multirow[t]{3}{*}{1.800} & \multirow[t]{3}{*}{0.150} \\
\hline Within groups & 16778.268 & 143 & \multirow{2}{*}{\multicolumn{2}{|c|}{117.331}} & & \\
\hline Total & 17412.000 & 146 & & & & \\
\hline
\end{tabular}

Table 5: ANOVA results for Jewish identity and gender

\begin{tabular}{lcclll}
\hline & Sum of squares & df & Mean square & F & Sig. \\
\hline Between groups & 117.673 & 1 & 117.6731 & 0.987 & 0.322 \\
Within groups & 17294.327 & 145 & 119.271 & & \\
Total & 17412.000 & 146 & & & \\
\hline
\end{tabular}

Table 6: ANOVA Results for Jewish Identity and Employment Status

\begin{tabular}{lcclll}
\hline & Sum of squares & df & Mean square & F & Sig. \\
\hline Between groups & 422.074 & 3 & 140.691 & 1.184 & \\
Within groups & 16989.926 & 143 & 118.811 & & \\
Total & 17412.000 & 146 & & & \\
\hline
\end{tabular}

Table 7: ANOVA Results for Jewish Identity and Volunteer

\begin{tabular}{|c|c|c|c|c|c|}
\hline & Sum of squares & df & Mean square & $\mathrm{F}$ & Sig. \\
\hline Between groups & 87.841 & 1 & 87.841 & 0.735 & 0.393 \\
\hline Within groups & 17324.159 & 145 & 119.477 & & \\
\hline Total & 17412.000 & 146 & & & \\
\hline
\end{tabular}


In NVivo, this process involved assigning transcript excerpts with meanings relevant to answering a research question to a node. When transcript excerpts indicated similar meanings relevant to answering a research question, they were assigned to the same node. Each node represented a code.

In the next step of the analysis, the data were themed. Theming the data involved grouping the codes with similar meanings or meanings that were related as different aspects of a single, overarching theme. In NVivo, this process involved grouping the nodes representing similar or related codes under a common parent node, which represented a theme.

Two major themes emerged. The first major theme, which was used to answer Research Question (RQ) 1, was: Identification with the Jewish faith is strongest in relation to the value placed on family. The second major theme, used to answer Research Question 2, was: Volunteering is identified as an expression of personal inclination rather than of faith. The following presentation of the findings is organized by research question. The discussion related to each research question includes descriptions of the codes that were grouped to form the themes. Direct quotations from the data are presented as evidence for all findings.

Theme1: Identification with the Jewish Faith Is Strongest in Relation to the Value Placed on Family

Theme 1 was used to answer RQ1, which was: To what extent do congregants identify with their faith? Focus group participants expressed that they strongly identified with their faith and that they experienced this identification most strongly through the value it placed on the family and on the congregation as an extension of the family. Nine excerpts from the focus group transcript were grouped into the four codes from which this theme emerged. Table 9 indicates the codes grouped to form this theme.

Participants strongly identified with the family values they associated with the Jewish faith. A participant stated:

"The basic element of Judaism is family. Remember: We started as a family of Abraham and Sarah and so, when you take it in that light, you're just working with your family. The same as I do with my children, I do with everybody else that's of my faith. I'm caring for my family."

A participant experienced Jewish identity as an imperative to help others in part because of the high value placed on setting a good example for one's children:

"I think it's important to give back to the Temple and also work with people. It's setting a good role model for my child, knowing the importance of Judaism and working to help others."

Strongly identifying with the importance placed on family in the Jewish faith further enhanced participants'
Jewish identity when they broadened their perception of family to include the congregation:

"I grew up where everybody was Jewish, whether you affiliated with one of the 10 synagogues in our town or not and coming here ... we were drawn to the Temple before we decided whether to move here .. . In order to find our like, we joined the Temple immediately and that was our family. Temple life was our family. We didn't have brothers, sisters, or anything. We just had our children and that was our family."

The high value placed on family and on the congregation as an extension of the family in the Jewish faith contributed to a sense of strong identification with other members of the Jewish community. Some participants experienced this sense of communion with other members of their faith most strongly when they were in the company of people of other faiths:

"We're invited to a lot of interfaith gathering
and I guess I feel Jewish most often when we
wind up at Christian events and [being Jewish]
just doesn't fit anymore."

\section{Theme2: Volunteering Is Identified as an Expression of Principle}

Theme 2 was used to answer RQ2, which was: To what extent are current volunteer opportunities seen as potential expressions of their faith? Theme 2 included two subthemes: (1) Volunteering as a principle and (2) reconciling the drive to volunteer with opportunity and capacity. A total of 32 excerpts from the transcript were grouped into 10 codes to form this theme. Table 10 indicates the subthemes and codes associated with Theme 2.

\section{Subtheme1: Volunteering as a Principle}

Participants expressed that they did not identify the value of volunteering or the sense of obligation to do so with any specific religious faith. A participant stated:

\section{"I think [volunteering is] important, no matter what religion or what you're working for. I'm involved in other areas that are not related to the Temple, so I think giving your service and helping others is important no matter what."}

Further, one participant echoed:

"I have to agree with that. I think it has nothing to do with your faith, but your personality, just giving of yourself, if you so want to, whether you do it at the Temple or you do it in the greater community." 
Meanwhile, another participant highlighted that being part of the community means being one in helping and serving, no matter what one's religion is. The participant noted: "I agree, I think the community needs you as much as the Temple, but you still want to be a part of the community."

A participant described the drive that motivated volunteering as individual rather than faith-dependent: "If you have the need to volunteer, if you have the drive to volunteer, or the want to volunteer, no matter what your life experiences . . you're going to find opportunities to volunteer." Another participant used similar language to describe the motivation to volunteer as an individual inclination: "If you're inclined to volunteer, you're out there. There's plenty of need for you." In addition, participants described the personal benefits volunteers derived from their service as being universal. For example, a participant described volunteering as a check against idleness and a way to meet people:

"Rather than sitting at home and vegetating, I think itis very important that you participate, not necessarily in only the Jewish community, but in the community at large and I think that's what keeps you going, too... It keeps my mind active and getting to know other people in different circles, both here and in other cities."

A different participant described the motivation to volunteer as intrinsic: "One volunteers to feel better about themselves, so you help the refugees, or those in need of food, or raise funds for some organization. You feel good. You come away from a volunteer experience feeling good." One participant described the motivation to volunteer as a need to be active within and close to the Jewish community, but for universal reasons of survival rather than faith-specific reasons, stating that volunteering served "A need to be a part of [the Jewish] community. Being that I came here as a stranger and had to make a life for myself, I need the Jewish community in order to survive." When volunteerism was identified with the Jewish faith, the Jewish faith was perceived as a means to express a pre-existing drive to volunteer rather than volunteerism being perceived as a means of expressing the Jewish faith. One participant suggested: "I've always been involved in volunteering in one way or another. My decision to convert to Judaism was based in large part on the amount of work reform Jews do out in the world." Volunteering was also identified with the Jewish faith when it was perceived as a means of meeting a learned, faith-based obligation, rather than as a positive expression of faith. Another participant suggested: "Many people were brought up Jewish and brought up with the ethical laws and so, they might be geared toward volunteerism because of that."

\section{Subtheme2: Volunteering According to Opportunity and Capacity}

In addition to perceiving volunteerism as an expression of an individual drive or inclination, participants perceived volunteerism as an expression of individual circumstances, including the opportunities and constraints encountered by each individual with the drive to volunteer. A participant described the reaction elicited when the individual drive was met by chance with opportunities for expression: "I found that there were committees that I didn't even know existed . . . and some of them intrigued me. I thought, 'Oh, there's something beyond [name of committee redacted] that I could [be] involved in." The desire to pursue opportunities for volunteerism was constrained by individual circumstances, however, as a participant indicated: "It's a matter of how much do you give? How much do you involve yourself?"

Table 8: Focus group participant demographics

\begin{tabular}{lll}
\hline Participant & Gender & Age range \\
\hline P1 & Male & $80-89$ \\
P2 & Male & $50-59$ \\
P3 & Female & $50-59$ \\
P4 & Female & $90-99$ \\
P5 & Female & $70-79$ \\
P6 & Female & $60-69$ \\
P7 & Female & $50-59$ \\
\hline
\end{tabular}

Table 9: Theme 1 codes

\begin{tabular}{ll}
\hline $\begin{array}{l}\text { Theme } \\
\text { Codes }\end{array}$ & $\begin{array}{l}n \text { of references } \\
\text { in transcript }\end{array}$ \\
\hline $\begin{array}{l}\text { Identification with the Jewish } \\
\text { faith is strongest in relation to } \\
\text { the value placed on family }\end{array}$ & 9 \\
Faith and family & \\
Immersion in the homeland & 5 \\
When surrounded by non-Jews & 1 \\
Precept of helping others & 2 \\
\hline
\end{tabular}

Table 10: Theme 2 codes

\begin{tabular}{ll}
\hline $\begin{array}{l}\text { Theme Subtheme } \\
\text { Code }\end{array}$ & $\begin{array}{l}n \text { of references } \\
\text { in transcript }\end{array}$ \\
\hline $\begin{array}{l}\text { Volunteering is identified as an } \\
\text { expression of principle }\end{array}$ & 32 \\
Volunteering as a principle & 23 \\
Faith calling toward volunteerism & 3 \\
Participating as community member & 6 \\
$\quad$ Values in volunteering & 7 \\
$\quad$ Volunteering outside Jewish community & 6 \\
$\quad$ Volunteerism drawing to faith & 1 \\
Volunteering according to opportunity & \\
and capacity & 9 \\
Broad awareness & 1 \\
$\quad$ Challenges in recruiting volunteers & 1 \\
$\quad \begin{array}{l}\text { Could increase awareness } \\
\text { Lactors impacting capacity }\end{array}$ & 2 \\
attending temple & 3 \\
\hline
\end{tabular}


A participant referred to specific, circumstantial constraints related to time and opportunity that impeded volunteering: "I' $m$ working and travelling and I don't have the time and I'm not in town to be able to do it, so I don't look into it as much as I would if I was retired." Similarly, another participant noted that being retired, not retired or working, can affect what you know and, in turn, may also impact the time you have to allocate to reading all of the newsletters, emails and bulletins. To that end, a participant highlighted: "I thought I was pretty plugged in and then the other night, we all signed in (Zoom lobby) for our various committees and I found that there were committees that I didn't even know existed."

Another participant described the Temple's ability to recruit volunteers as curtailed by its decreasing pool of young members who could be compelled by their parents to volunteer: "Our school-age population has shrunk. We have lesser the folks that are the indentured servants of parents. There's fewer people to draft for things because they're just not around." The constraints associated with having fewer young members resulted in a transfer of volunteer tasks to older members, who might have their own constraints on taking up the additional burden: “There's a greater burden being put on members who don't have sons and daughters affiliated with the Temple."

\section{Summary of Findings}

Two research questions were used to guide this study. The first research question was: To what extent do congregants identify with their faith? The theme that emerged during data analysis to answer this question was: Identification with the Jewish faith is strongest in relation to the value placed on family. In relation to this theme, participants indicated that they strongly identified with the Jewish faith and that they felt their identification most strongly when they were acting on the high value their faith placed on family and on the congregation as an extension of the family.

The second research question was: To what extent are current volunteer opportunities seen as potential expressions of their faith? The theme that emerged to answer this research question was: Volunteerism is identified as an expression of personal inclination rather than of faith. Participants perceived the drive to volunteer as being either intrinsic to the individual or as intrinsically motivated by the fulfillment enjoyed by volunteers. When volunteering was associated with the Jewish faith, the Jewish faith was seen as a means of expressing the drive to volunteer rather than vice versa. Alternatively, volunteering was perceived as a means of participating more fully in the congregation in order to obtain assistance in meeting practical needs.

The theme that emerged here, similar to the statistical findings, is that faith is not an exclusive or even a predominant reason that study participants volunteer. Rather, participants perceived the drive to volunteer as being either intrinsic to the individual or as intrinsically motivated by the fulfillment enjoyed by volunteers. When volunteering was associated with the Jewish faith, the Jewish faith was seen as a means of expressing the drive to volunteer rather than vice versa, or volunteering was perceived as a means of participating more fully in the congregation in order to obtain assistance with meeting practical needs.

The implications of these quantitative and qualitative results, for future research, theory and practice, are presented and discussed in the Conclusion. Additionally, the strengths and weaknesses of the results presented here are discussed in terms of internal validity, external validity, theoretical validity and measurement validity and reliability.

\section{Conclusion}

The decline in the number of volunteers is universal and is not limited to North Carolina or to this Temple, which is supported by the literature. Both the literature and the research reveal that identity is a component of the motivating factors that influence an individual's decision to volunteer and as it relates to the Temple, the connection between volunteerism and intrinsic motivation (satisfaction and Mitzvah) is clearly present. When volunteers feel the motivational pull toward identitycongruent actions, it further builds on their identity (in this case, their Jewish identity).

Despite the limitations of a small population sampled, this research is valuable as it provides insight into what motivates individuals to volunteer in conjunction with the depth of their Jewish identity. Given the universal decline in volunteerism, now is the time to address the issue, formulate an action plan and energize and motivate both the existing and future cohort of volunteers at the Temple.

\section{Acknowledgement}

A special thanks to the Temple and all who participated in this research.

\section{Ethics}

The author confirms that there is no conflict of interest and no funding to declare. No part of this manuscript is being considered for publication in whole or in part elsewhere. The researcher received IRB approval from Vanderbilt University.

\section{References}

Alexander, A., Kim, S. B., \& Kim, D. Y. (2015). Segmenting volunteers by motivation in the 2012 London Olympic Games. Tourism Management, 47, 1-10. https://doi.org/10.1016/j.tourman.2014.09.002 
Altman, A. N., Inman, A. G., Fine, S. G., Ritter, H. A., \& Howard, E. E. (2010). Exploration of Jewish ethnic identity. Journal of Counseling \& Development, 88(2), 163-173. https://onlinelibrary.wiley.com/doi/abs/10.1002/j.15 56-6678.2010.tb00005.x

Beyerlein, K., \& Hipp, J. R. (2006). From pews to participation: The effect of congregation activity and context on bridging civic engagement. Social Problems, 53(1), 97-117. https://doi.org/10.1525/sp.2006.53.1.97

Chase, E. R. (2018). Measuring the Positivity of Jewish Experiences: Scale Development and Validation (Doctoral dissertation, Alliant International University).

https://search.proquest.com/openview/689595f0e08 3d4fc8d3badbf02a94d80/1?pqorigsite $=$ gscholar $\& \mathrm{cbl}=18750 \&$ diss $=\mathrm{y}$

Cohen, A. B., \& Hill, P. C. (2007). Religion as culture: Religious individualism and collectivism among American Catholics, Jews and Protestants. Journal of personality, 75(4), 709-742. https://onlinelibrary.wiley.com/doi/abs/10.1111/j.14 67-6494.2007.00454.x

Cohen, I. K. (2006). The evolution of wound healing. In The diabetic foot (pp. 51-57). Humana Press. https://link.springer.com/chapter/10.1007/978-159745-075-1_3

Elmore, K. C., \& Oyserman, D. (2012). If 'we'can succeed, 'I'can too: Identity-based motivation and gender in the classroom. Contemporary educational psychology, 37(3), 176-185. https://doi.org/10.1016/j.cedpsych.2011.05.003

Finkelstein, M. A. (2009). Intrinsic vs. extrinsic motivational orientations and the volunteer process. Personality and Individual Differences, 46(5-6), 653-658. https:/www.sciencedirect.com/science/article/abs/pi i/S0191886909000221

Friedlander, M. L., Friedman, M. L., Miller, M. J., Ellis, M. V., Friedlander, L. K., \& Mikhaylov, V. G. (2010). Introducing a brief measure of cultural and religious identification in American Jewish identity. Journal of Counseling Psychology, 57(3), 345. https://psycnet.apa.org/record/2010-14017-009

Forbes, K. F., \& Zampelli, E. M. (2014). Volunteerism: The influences of social, religious and human capital. Nonprofit and Voluntary Sector Quarterly, 43(2), 227-253.

https://journals.sagepub.com/doi/abs/10.1177/08997 64012458542

Gage III, R. L., \& Thapa, B. (2012). Volunteer motivations and constraints among college students: Analysis of the volunteer function inventory and leisure constraints models. Nonprofit and Voluntary Sector Quarterly, 41(3), 405-430. https://journals.sagepub.com/doi/abs/10.1177/08997 64011406738
Hodgkinson, V. A. (1990). Mapping the non-profit sector in the United States: implications for research. Voluntas: International Journal of Voluntary and Nonprofit Organizations, 1(2), 6-32. https://link.springer.com/article/10.1007\%252FBF0 1397436

Johnston, J. B. (2013). Religion and volunteering over the adult life course. Journal for the Scientific Study of Religion, 52(4), 733-752. https://onlinelibrary.wiley.com/doi/abs/10.1111/jssr. 12065

Johnson, K. A., Memon, R., Alladin, A., Cohen, A. B., \& Okun, M. A. (2015). Who helps the Samaritan? The influence of religious vs. secular primes on spontaneous helping of members of religious outgroups. Journal of Cognition and Culture, 15(1-2), 217-231. https://doi.org/10.1163/1568537312342147

Kang, M. (2016). Moderating effects of identification on volunteer engagement: An exploratory study of a faith-based charity organization. Journal of Communication Management. https://doi.org/10.1108/JCOM-08-2014-0051

Klein, J. G., Lowrey, T. M., \& Otnes, C. C. (2015). Identity-based motivations and anticipated reckoning: Contributions to gift-giving theory from an identity-stripping context. Journal of Consumer Psychology, 25(3), 431-448. https://doi.org/10.1016/j.jcps.2015.01.003

Krieger, A. (2010). The role of family functioning in ethnic identity and well-being in Jewish late adolescent women. University of Rhode Island. https://search.proquest.com/openview/45ba931aaf47 14378de38b89f742f4fa/1?pqorigsite $=$ gscholar $\& \mathrm{cbl}=18750 \&$ diss $=\mathrm{y}$

Kwok, Y. Y., Chui, W. H., \& Wong, L. P. (2013). Need satisfaction mechanism linking volunteer motivation and life satisfaction: A mediation study of volunteers subjective well-being. Social indicators research, 114(3), 1315-1329. https://doi.org/10.1007/s11205012-0204-8

Levy, L. (2012). Volunteerism in the Jewish Community: A Comparative Study. Yeshiva University. https://search.proquest.com/openview/5437146324e e3169675d7ffa9fe60407/1?pqorigsite $=$ gscholar $\& \mathrm{cbl}=18750 \&$ diss $=\mathrm{y}$

Lewis Jr, N. A., \& Oyserman, D. (2016). Using identitybased motivation to improve the nation's health without breaking the bank. Behavioral Science \& Policy, 2(2), 24-38. https://doi.org/10.1353/bsp.2016.0013

Lowe, G., Willis, G., \& Gibson, K. (2019). You do what? A qualitative investigation into the motivation to volunteer with circles of support and accountability. Sexual Abuse, 31(2), 237-260. https://doi.org/10.1177/1079063217729157 
Manetti, G., Bellucci, M., Como, E., \& Bagnoli, L. (2015). Investing in volunteering: Measuring social returns of volunteer recruitment, training and management. VOLUNTAS: International Journal of Voluntary and Nonprofit Organizations, 26(5), 2104-2129. https://link.springer.com/article/10.1007/s11266014-9497-3

Merino, S. M. (2013). Religious social networks and volunteering: Examining recruitment via close ties. Review of Religious Research, 55(3), 509-527. https://link.springer.com/article/10.1007/s13644013-0113-6

Mencken, F. C., \& Fitz, B. (2013). Image of God and community volunteering among religious adherents in the United States. Review of Religious Research, 55(3), 491-508. https://link.springer.com/article/10.1007/s13644013-0115-4

Nauta, R. (2007). People make the place: Religious leadership and the identity of the local congregation. Pastoral Psychology, 56(1), 45-52. https://link.springer.com/article/10.1007/s11089007-0098-6

Oyserman, D. (2007). Social identity and self-regulation. In A. W. Kruglanski\& E. T. Higgins (Eds.), Social psychology: Handbook of basic principles (p. 432453). The Guilford Press. https://psycnet.apa.org/record/2007-11239-018

Oyserman, D. (2009). Identity-based motivation: Implications for action-readiness, proceduralreadiness and consumer behavior. Journal of Consumer Psychology, 19(3), 250-260. https://doi.org/10.1016/j.jcps.2009.05.008

Oyserman, D. (2015). Identity-based motivation. Emerging trends in the social and behavioral sciences: An interdisciplinary, searchable and linkable resource, 111. https://doi.org/10.1002/9781118900772.etrds0171

Penner, L. A. (2002). Dispositional and organizational influences on sustained volunteerism: An interactionist perspective. Journal of social issues, 58(3), 447-467. https://spssi.onlinelibrary.wiley.com/doi/abs/10.111 1/1540-4560.00270

Punzi, E., \& Frischer, J. (2016). Voluntary work with sporting activities for Jewish children and teenagers: commitment to inclusiveness, Jewish identity and a future Jewish life-an interview study. Journal of Modern Jewish Studies, 15(3), 419-435. https://www.tandfonline.com/doi/abs/10.1080/1472 5886.2016.1185212

Rosen, L. (2006). Expecting the unexpected: Cultural components of Arab governance. The Annals of the American Academy of Political and Social Science, 603(1), 163-178.
Schlosser, L. Z. (2006). Affirmative psychotherapy for American Jews (Vol. 43, No. 4, p. 424). Educational Publishing Foundation. https://psycnet.apa.org/record/2006-23019-006

Snyder, M., \& Omoto, A. M. (1992). Who helps and why? The psychology of AIDS volunteerism. In S. Spacapan \& S. Oskamp (Eds.), The Claremont Symposium on Applied Psychology. Helping and being helped: Naturalistic studies (p. 213-239). Sage Publications, Inc. https://psycnet.apa.org/record/1992-97275-007

Taniguchi, H., \& Thomas, L. D. (2011). The influences of religious attitudes on volunteering. VOLUNTAS: International Journal of Voluntary and Nonprofit Organizations, 22(2), 335-355. https://link.springer.com/article/10.1007/s11266010-9158-0

Twenge, J. M., Exline, J. J., Grubbs, J. B., Sastry, R., \& Campbell, W. K. (2015). Generational and time period differences in American adolescents' religious orientation, 1966-2014. PloS one, 10(5), e0121454.

https://doi.org/10.1371/journal.pone.0121454

U.S. Department of Labor, Bureau of Labor Statistics. (2005). Volunteering in the United States 2005 (USDLPublication No. 05-2278). https://www.bls.gov/news.release/archives/volun 12092005.pdf

U.S. Department of Labor, Bureau of Labor Statistics. (2007). Volunteering in the United States 2006 (USDL Publication No. 07-0019). https://www.bls.gov/news.release/archives/volun_ 01102007.pdf

U.S. Department of Labor, Bureau of Labor Statistics. (2016). Volunteering in the United States 2015 (USDLPublicationNo. 16-0363). http://www.bls.gov/news.release/pdf/volun.pdf

Van Tienen, M., Scheepers, P., Reitsma, J., \& Schilderman, H. (2011). The role of religiosity for formal and informal volunteering in the Netherlands. Voluntas: International Journal of Voluntary and Nonprofit Organizations, 22(3), 365-389. https://doi.org/10.1007/s11266-0109160-6

Wemlinger, E., \& Berlan, M. R. (2016). Does gender equality influence volunteerism? A cross-national analysis of women's volunteering habits and gender equality. VOLUNTAS: International Journal of Voluntary and Nonprofit Organizations, 27(2), 853-873. https://doi.org/10.1007/s11266015-9595-X

Wilson, J. (2012). Volunteerism research: A review essay. Nonprofit and voluntary sector quarterly, 41(2),

$176-212$ https://doi.org/10.1177/0899764011434558 